\title{
ANALISIS ATRIBUT KEAMANAN TERHADAP PERBAIKAN \\ PROTOKOL GROUP KEY TRANSFER : PROTOKOL HSU
}

\author{
I Made Mustika Kerta Astawa \\ Lembaga Sandi Negara \\ Kadek19_kaptainboy@yahoo.com
}

Rahmi Nurazizah

Lembaga Sandi Negara

\begin{abstract}
Protocol Hsu et.al first introduced in 2012 and is the protocol type Group Key Transfer based Linear Shamir's Secret Sharing Scheme (LSSS). The main idea of this protocol is to use m-secret sharing perspective. This protocol assumes that the difficulty of discrete logarithm problem (DLP) (ie given $p k_{i}=g^{s k_{i}}$ is computationally very difficult/not feasible to count $\left.s k_{i}, i=1, \ldots, m\right)$ and Cryptographyc Diffie Hellman (CDH) (ie given $p k_{i}$ and $p k_{j}$ it is computationally very difficult/not feasible to count $\left.g^{s k_{i} s k_{j}}, i, j=1, \ldots, m, i \neq j\right)$ in $G$. Thus, it needs to analyze the security attributes to this mechanism Protocol Hsu. Good cryptographic protocols should meet the security attributes Known Security Key, Key-Compromise Impersonation Resillience, Unknown Key-Share Resillience, Key Control and Key Confirmation.
\end{abstract}

Keywords: Security Attribute, cryptographyc protocol, Protocol Hsu.

\begin{abstract}
ABSTRAK. Protokol Hsu dan kawan-kawan diperkenalkan pertama kali pada tahun 2012 dan merupakan jenis protokol Group Key Transfer berbasis Linear Shamir's Secret Sharing Scheme (LSSS). Gagasan utama dari protokol ini adalah menggunakan perspektif $m$-secret sharing. Protokol ini mengasumsikan bahwa sulitnya Discrete Logarithm Problem (DLP) (yaitu diberikan $p k_{i}=g^{s k_{i}}$ merupakan komputasi yang sangat sulit/tidak layak untuk menghitung $s k_{i}, i=1, \ldots, m$ ) dan Cryptographyc Diffie Hellman (CDH) (yaitu diberikan $p k_{i}$ dan $p k_{j}$ merupakan komputasi yang sangat sulit/tidak layak untuk menghitung $\left.g^{s k_{i} s k_{j}}, i, j=1, \ldots, m, i \neq j\right)$ di $G$. Sehingga, perlu dilakukan analisis atribut keamanan terhadap mekanisme Protokol Hsu ini. Protokol kriptografi yang baik seharusnya memenuhi atribut keamanan Known Key Security, Key-Compromise Impersonation Resillience, Unknown Key-Share Resillience, Key Control dan Key Confirmation.
\end{abstract}

Kata Kunci: Atribut Keamanan, Protokol Kriptografi, Protokol Hsu. 


\section{PENDAHULUAN}

\subsection{Latar belakang}

Protokol Key establishment merupakan salah satu prinsip dasar dalam membangun kriptografi, dimana didefinisikan sebagai proses untuk menyediakan kunci rahasia bersama diantara dua atau lebih pihak yang berkomunikasi, untuk penggunaan kriptografi berikutnya. Terdapat dua macam protokol key establishment yaitu protokol key transport dan protokol key agreement [1]. Protokol key transport dibuat untuk komunikasi dan transmisi kunci secara aman oleh dua pihak entitas atau lebih, namun yang aktif dalam pembentukan kunci hanya salah satu pihak. Sedangkan pada protokol key agreement, diantara kedua entitas memberikan kontribusi informasi yang digabungkan untuk membuat kunci rahasia [2].

Protokol key establishment secara tradisional berada diantara protokol yang sulit untuk dibangun dan meyakinkan proses pertukaran kunci dapat dilakukan secara aman. Terdapat beberapa tantangan terkait proses pertukaran kunci antara lain [3]:

a. Memastikan kunci yang dipertukarkan sehingga pengirim dan penerima dapat melakukan proses enkripsi dan dekripsi

b. Mencegah celah kebocoran kunci

c. Memberikan bukti kepada pengirim bahwa pesan dienkripsi oleh pihak yang mengaku mengirimkan pesan.

Protokol Hsu merupakan protokol kriptografi untuk pertukaran kunci yang memanfaatkan perspektif $m$-secret sharing untuk menambah keamanannya. Namun, dalam implementasinya masih terdapat kelemahan yang dapat membahayakan kunci rahasia yang dipertukarkan. Untuk itu, pada makalah ini dilakukan perbaikan terhadap protokol Hsu untuk meningkatkan aspek keamanan protokol, dan mencoba untuk menemukan analisis keamanan berdasarkan atribut keamanan protokol kriptografi. 


\subsection{Maksud dan Tujuan}

Melihat kondisi saat ini banyaknya penerapan protokol kriptografi terutama protokol Key Establishment yang digunakan untuk menyediakan kunci rahasia secara aman seperti protokol Hsu, maka dalam penelitian ini penulis bermaksud memberikan pemahaman dan mengidentifikasi atribut keamanan yang yang telah dipenuhi sehingga dapat dikatakan protokol Hsu terhindar dari serangan active attack. Adapun tujuan yang ingin dicapai dari analisis protokol Hsu yaitu :

a. Melakukan perbaikan terhadap protokol Hsu agar terhindar dari serangan yang mungkin dilakukan

b. Mengidentifikasi atribut keamanan sehingga dapat dikatakan protokol Hsu merupakan protokol kriptografi yang aman.

\section{METODE PENELITIAN}

Pada penelitian ini, penulis menggunakan metode penelitian kepustakaan dan analisis awal. Metode tersebut berupa deskripsi penelitian yang dihasilkan atas kajian referensi pustaka yang didukung dengan analisis atribut keamanannya. Sama seperti bentuk penelitian lainnya, penelitian kepustakaan dan analisis ini bertujuan untuk mengklarifikasi atau memperluas pemahaman dan pengetahuan. Tahapan proses penelitian ini adalah sebagai berikut:

1. Pengumpulan data

Melakukan pengumpulan referensi dari beberapa buku atau referensi lain mengenai protokol key establishment, protokol key transport, atribut keamanan protokol, serta protokol Hsu.

2. Identifikasi

Melakukan proses identifikasi lebih lanjut tentang kelemahan dari protokol Hsu.

3. Analisis data

Analisis hasil pengumpulan data dan identifikasi yang telah dilakukan, sehingga didapat analisis atribut keamanan dari protokol Hsu. 
4. Pengambilan Kesimpulan

Pengambilan simpulan hasil penelitian.

\section{HASIL DAN PEMBAHASAN}

\subsection{Deskripsi Protokol Hsu}

Protokol Hsu dan kawan-kawan diperkenalkan pertama kali pada tahun 2012 dan merupakan jenis protokol GKT berbasis Linear Shamir's Secret Sharing Scheme (LSSS). Gagasan utama dari protokol ini adalah menggunakan perspektif m-secret sharing [4]. Penjelasan lengkap tentang tahapan dari protokol Hsu dan kawan-kawan adalah sebagai berikut :

a. Inisialisasi

Anggap $G$ merupakan perkalian grup cyclic pada order $p$, dengan pembangkit $g$ dimana $p$ merupakan sebuah bilangan prima besar (misalnya $p^{\prime}=\frac{p-1}{2}$ merupakan prima juga);

b. Registrasi Pengguna

Setiap pengguna $U_{i}, i=1, \ldots, m$ memiliki pasangan kunci publik dan private $\left(p k_{i}, s k_{i}\right) \operatorname{dimana} p k_{i}=g^{s k_{i}} \operatorname{pada} G$.

c. Putaran 1

Pengguna $U_{1}$ :

1) Pilih $r_{1} \leftarrow^{R} Z_{p}^{*}$;

2) Mengirimkan permintaan pembangkitan kunci :

$$
U_{1} \rightarrow *:\left(\left\{U_{1}, \ldots, U_{t}\right\}, r_{1}, p k_{1}\right)
$$

d. Putaran 2

Setiap pengguna $U_{i}, i=2, \ldots, t$ :

1) Pilih $r_{1} \leftarrow^{R} Z_{p}^{*}$;

2) Hitung $S_{i}=p k_{1}^{s k_{1} r_{i} r_{1}}$ merupakan shared secret dengan $U_{1}$ dan $\operatorname{Auth}_{i}=h\left(S_{i}, r_{1}\right)$ 
3) Broadcast :

$$
U_{1} \rightarrow^{*}:\left(r_{i}, p k_{i}, A u t h_{i}\right)
$$

e. Putaran 3

Pengguna $U_{1}$ :

1) Hitung $S_{i}=p k_{1}^{s k_{1} r_{i} r_{1}}, i=2, \ldots, t$;

2) Mengecek jika Auth $_{i}=h\left(S_{i}, r_{1}\right), i=2, \ldots, t$

Jika sedikitnya satu saja tidak sama, maka selesai;

3) Pilih group key $k \leftarrow^{R} Z_{p}^{*}$, membagi setiap rahasia $S_{i}$ menjadi dua bagian $S_{i}=x_{i} \| y_{i} \quad$ dan menghitung $t-1$ nilai $t-1$, dimana $T_{i}=\left(y_{i} v\left(x_{i}\right), r\right)$ merupakan inner product pada vektor $T_{i}=\left(y_{i} v\left(x_{i}\right), r\right), \quad i=2, \ldots, t$ dan $r=\left(r_{1}, \ldots, r_{t}\right)$

4) Menghitung Auth $=h\left(k, U_{1}, \ldots, U_{t}, r_{1}, \ldots, r_{t}, K_{2}, \ldots, K_{t}\right)$;

5) Broadcast :

$$
U_{1} \rightarrow *:\left(A u t h, K_{2}, \ldots, K_{t}\right)
$$

f. Perhitungan Kunci

Setiap pengguna $U_{i}, i=2, \ldots, t$ :

1) Menghitung inner product $T_{i}=\left(y_{i} v\left(x_{i}\right), r\right)$, merecover group key $k=T_{i}+K_{i}$

2) Mengecek jika Auth $=\left(k, U_{1}, \ldots, U_{t}, r_{1}, \ldots, r_{t}, K_{2}, \ldots, K_{t}\right)$

Jika tidak sama, maka berhenti.

Disebutkan bahwa perbedaan utama dari sisa protokol yang diuraikan dalam bagian ini adalah konstruksi tidak melakukan konfirmasi/bertanya ke KGC eksternal dan karena itu tidak ada pendaftaran yang diperlukan sebelumnya ke KGC. Inisiator $U_{1}$ melakukan peran KGC dan menetapkan kunci rahasia yang sama dengan masing-masing peserta lain pada saat runtime, yang sesuai dengan kunci jangka panjang, namun memiliki keuntungan dimana selalu diperbaharui 
untuk setiap sesi. Namun, setiap peserta $U_{i}, i=1, \ldots, m$ harus memiliki pasangan kunci publik-rahasia $\left(p k_{i}, s k_{i}\right)$ yang disahkan oleh otoritas yang terpercaya dengan sertifikat.

Protokol ini mengasumsikan bahwa sulitnya Discrete Logarithm Problem (DLP) (yaitu diberikan $p k_{i}=g^{s k_{i}}$ merupakan komputasi yang sangat sulit/tidak layak untuk menghitung $\left.s k_{i}, i=1, \ldots, m\right)$ dan Cryptographyc Diffie Hellman $(\mathrm{CDH})$ (yaitu diberikan $p k_{i}$ dan $p k_{j}$ merupakan komputasi yang sangat sulit/tidak layak untuk menghitung $\left.g^{s k_{i} k_{j}}, i, j=1, \ldots, m, i \neq j\right)$ di $G$.

\subsection{Perbaikan Pada Protokol Hsu}

Serangan sebelumnya (active attack) disebabkan oleh pemalsuan proses otentikasi, dimana group key $k$ tidak benar otentik yang berasal dari inisiator $U_{1}$. Hal ini memungkinkan penyerang untuk meniru $U_{1}$ dan mengirimkan hasil yang dimodifikasi tetapi proses otentikasi terlihat valid yang membantu dia untuk mencapai tujuannya.

Cara sepele untuk mencegah serangan ini (active attack) yaitu adanya Tahap Konfirmasi Kunci yang menjamin bahwa semua pengguna memiliki kunci yang benar Setiap pengguna dapat menandatangani group key yang diperoleh dan broadcast kepada anggota lain [5]. Dalam rangka mempertahankan kerahasiaan dari nilainya, kuncinya dilakukan proses hash, bersama dengan beberapa nilai umum yang digunakan selama pelaksanaan protokol. Kelemahan dari solusi ini adalah jelas bahwa biaya komputasi dan transmisi meningkat secara signifikan. Penambahan tahap pada protokol asli mengakibatkan setiap pengguna menghasilkan satu tanda tangan dan verifikasi $t-1$ lainnya, masing-masing tahap tambahan komunikasi diperlukan dan pesan $t$ lebih pesan bradcast yang beredar di jaraingan. Selebihnya, pendekatan ini tidak menghilangkan serangan yang mungkin dilakukan, tetapi hanya mengungkapkan selama proses pembangkitan kunci, di proses pelaksanaan aplikasi. Perbaikan terhadap protokol Hsu sebagai berikut : 
a. Inisialisasi

Anggap $G$ merupakan perkalian grup cyclic pada order $p$, dengan pembangkit $g$ dimana $p$ merupakan sebuah bilangan prima besar (misalnya $p^{\prime}=\frac{p-1}{2}$ merupakan prima juga);

b. Registrasi Pengguna

Setiap pengguna $U_{i}, i=1, \ldots, m$ memiliki pasangan kunci publik dan private $\left(p k_{i}, s k_{i}\right) \operatorname{dimana} p k_{i}=g^{s k_{i}} \operatorname{pada} G$.

c. Putaran 1

Pengguna $U_{1}$ :

1) Pilih $r_{1} \leftarrow^{R} Z_{p}^{*}$;

2) Mengirimkan permintaan pembangkitan kunci :

$$
U_{1} \rightarrow *:\left(\left\{U_{1}, \ldots, U_{t}\right\}, r_{1}, p k_{1}\right)
$$

d. Putaran 2

Setiap pengguna $U_{i}, i=2, \ldots, t$ :

1) Pilih $r_{1} \leftarrow^{R} Z_{p}^{*}$;

2) Hitung $S_{i}=p k_{1}^{s k_{1} r_{i} r_{1}}$ merupakan shared secret dengan $U_{1}$ dan $\operatorname{Auth}_{i}=h\left(S_{i}, r_{1}\right)$

3) Broadcast :

$U_{1} \rightarrow^{*}:\left(r_{i}, p k_{i}\right.$, Auth $\left._{i}\right)$

e. Putaran 3

Pengguna $U_{1}$ :

1) Hitung $S_{i}=p k_{1}^{s k_{1} r_{i} r_{1}}, i=2, \ldots, t$;

2) Mengecek jika $A u t h_{i}=h\left(S_{i}, r_{1}\right), i=2, \ldots, t$

Jika sedikitnya satu saja tidak sama, maka selesai;

3) Pilih group key $k \leftarrow^{R} Z_{p}^{*}$, membagi setiap rahasia $S_{i}$ menjadi dua bagian $S_{i}=x_{i} \| y_{i}$ dan menghitung $t-1$ nilai $K_{i}=k-T_{i}$, dimana $T_{i}=\left(y_{i} v\left(x_{i}\right), r\right)$ 
merupakan inner product pada vector $y_{i} v\left(x_{i}\right)=y_{i} \sum_{j=1}^{t} x_{i}^{j} e_{j}\left(e_{j}=(0, \ldots, 1, \ldots, 0)\right.$ dengan 1 pada posisi $\left.j\right), i=2, \ldots, t$ dan $r=\left(r_{1}, \ldots, r_{t}\right)$;

4) Menghitung Auth $=h\left(k, U_{1}, \ldots, U_{t}, r_{1}, \ldots, r_{t}, K_{2}, \ldots, K_{t}\right)$;

5) Broadcast :

$U_{1} \rightarrow *:\left(A u t h, K_{2}, \ldots, K_{t}\right)$

f. Perhitungan Kunci

Setiap pengguna $U_{i}, i=2, \ldots, t$ :

1) Menghitung inner product $T_{i}=\left(y_{i} v\left(x_{i}\right), r\right)$, me-recover group key $k=T_{i}+K_{i} ;$

2) Mengecek jika Auth $=\left(k, U_{1}, \ldots, U_{t}, r_{1}, \ldots, r_{t}, K_{2}, \ldots, K_{t}\right)$

Jika tidak sama, maka berhenti.

g. Konfirmasi Kunci

Setiap pengguna $U_{i}, i=1, \ldots, t$ :

1) Menghitung $V_{i}=\Sigma . \operatorname{Sign}_{U_{i}}\left(h\left(k, U_{1}, \ldots, U_{t}, r_{1}, \ldots, r_{t}, K_{2}, \ldots, K_{t}\right)\right)$;

2) Broadcast : $U_{i} \rightarrow^{*}: V_{i}$

3) Mengecek jika :

L.Verify $_{U_{j}}\left(h\left(k, U_{1}, \ldots, U_{t}, r_{1}, \ldots, r_{t}, K_{2}, \ldots, K_{t}\right), V_{j}\right)=1, j=1, \ldots, t, j \neq i$

Jika tidak sama, maka berhenti.

\subsection{Analisis Atribut Keamanan pada Protokol Hsu}

a. Known Key Security

Session key $k$ didasarkan pada nilai acak $S$. Setiap $k_{i}$ merupakan nilai independen antara keduanya baik yang sebelum ataupun berikutnya, sehingga pengungkapan session key yang rahasia saat ini tidak memiliki dampat terhadap session key lainnya. Maka dari itu, protokol ini memenuhi sifat known key security. 


\section{b. Key-Compromise Impersonation Resillience}

Jika kita asumsikan bahwa private key pihak A yaitu $\left(p k_{A}, s k_{A}\right)$ mengalami kebocoran, penyerang dapat menjalankan protokol ini dan mendapatkan material kunci yang sama dengan pihak B (Pihak B percaya telah membagi kunci dengan pihak A). Sehingga penyerang akan berpura-pura sebagai pihak A. Tetapi jika penyerang mengetahui $\left(p k_{A}, s k_{A}\right)$, mencoba untuk berpura-pura sebagai pihak $\mathrm{B}$, maka dia tidak dapat menghitung $p k_{B}=g^{s k_{B}}$, karena dia tidak mengetahui $s k_{B}$. Pihak A akan mendeteksi hal tersebut pada verifikasi $A u t h_{A}=h\left(S_{A}, r_{A}\right)$. Sehingga protokol ini memenuhi sifat key compromise impersonation resilience.

\section{c. Unknown Key-Share Resillience}

Jika kita asumsikan penyerang $\mathrm{C}$ menerapkan penyadapan menggunakan man in the middle dan memodifikasi pesan sesuka hatinya, dalam rangka untuk mencoba mengelabui salah satu pihak agar berbagi kunci dengannya. Tetapi karena diantara pihak yang terlibat menghitung nilai $k$ berdasarkan beberapa informasi publik $r$ dari setiap pihak yang ingin menyediakan material kunci dan selama nilai $k$ diverifikasi dari nilai $S$, maka serangan tersebut tidak bisa dilakukan. Sehingga protokol ini memenuhi sifat unknown key share resilience.

\section{d. Key Control}

Hanya nilai-nilai yang mengubah digunakan untuk membangkitkan session key $k$. Diantara pihak A dan B memilih nilai sebelum mereka mengetahui variabel yang dikenali untuk digunakan membangkitkan kunci. Sehingga setiap pihak tidak memiliki kemungkinan untuk memaksa mendapatkan nilai session key. Oleh karena itu, protokol ini memenuhi sifat key control.

\section{e. Key Confirmation}

Karena kedua belah pihak yang berkomunikasi memverifikasi nilai $S$ yang diterima dan menghitung nilai $k$, mereka dapat memverifikasi bahwa pihak lain menghitung nilai session key yang sama untuk komunikasi tersebut. Sehingga protokol ini memberikan key confirmation yang sangat kuat. 


\section{KESIMPULAN}

Kesimpulan yang dapat diperoleh adalah :

a. Protokol Hsu dan kawan-kawan diperkenalkan pertama kali pada tahun 2012 dan merupakan jenis protokol GKT berbasis Linear Shamir's Secret Sharing Scheme (LSSS). Gagasan utama dari protokol ini adalah menggunakan perspektif $m$-secret sharing.

b. Dilakukan perbaikan protokol Hsu untuk mencegah serangan active attack dengan menambah Tahap Konfirmasi Kunci yang menjamin bahwa semua pengguna memiliki kunci yang benar. Setiap pengguna dapat menandatangani group key yang diperoleh dan broadcast kepada anggota lain.

c. Perbaikan terhadap Protokol Hsu memenuhi atribut keamanan Known Key Security, Key-Compromise Impersonation Resillience, Unknown Key-Share Resillience, Key Control dan Key Confirmation.

\section{DAFTAR PUSTAKA}

[1] Boyd, C., dan Mathuria, A., Protocols for Authentication and Key Establishment, Springer Verlag, 2003.

[2] Ateniese, G., Steiner, M., dan Tsudik, G., Authenticated group key agreement and friends, Proceedings of the 5th ACM conference on Computer and com-munications security, CCS '98, New York, USA, 1998.

[3] Bellare, M. dan Rogaway, P., Entity Authentication and Key Distribution, Proceedings of the 13th Annual International Cryptology Conference on Advances in Cryptology, CRYPTO '93, London, UK, 1994.

[4] Florentina, R., Secret Sharing-Based Group Key Establishment, University of Bucharest Faculty of Mathematics and Computer Science, 2013.

[5] Wilson, S. B., Johnson, D., dan Menezes, A., Key agreement protocols and their security analysis, Proceedings of the 6th IMA International Conference on Cryptography and Coding, London, UK, 1997. 